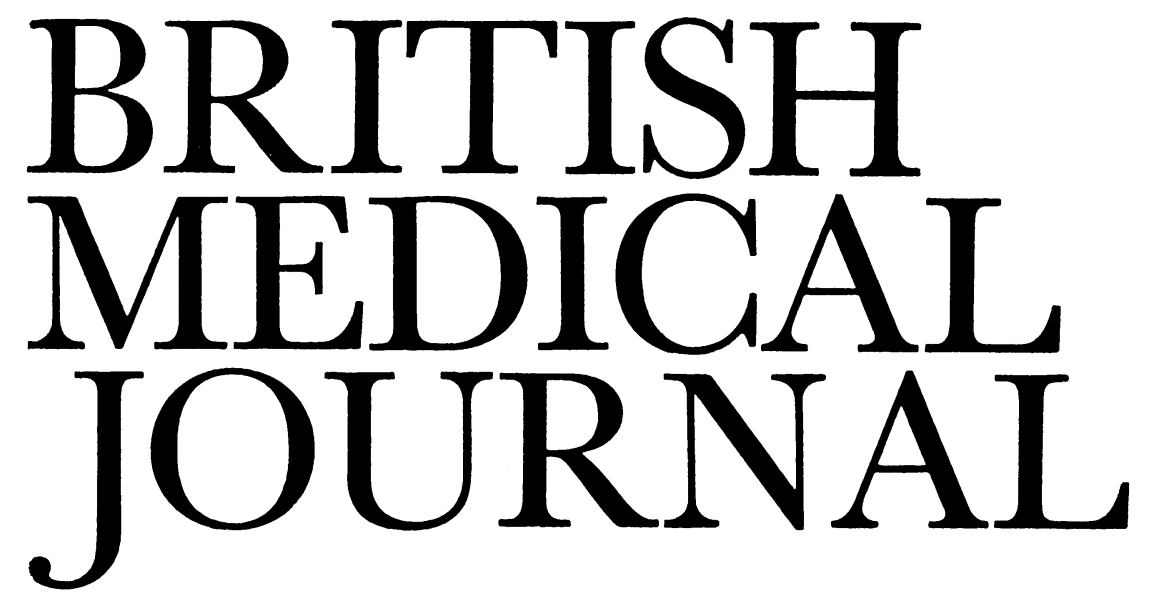

\title{
The end of clinical freedom
}

Clinical freedom is dead, and no one need regret its passing. Clinical freedom was the right-some seemed to believe the divine right-of doctors to do whatever in their opinion was best for their patients. In the days when investigation was non-existent and treatment as harmless as it was ineffective the doctor's opinion was all that there was, but now opinion is not good enough. If we do not have the resources to do all that is technically possible then medical care must be limited to what is of proved value, and the medical profession will have to set opinion aside.

"The active management of myocardial infarction" makes a good example, ${ }^{1}$ though similar topics could doubtless be found in any medical specialty. In theory restoring the blood supply to heart muscle after occlusion of a coronary artery is a highly desirable aim, and there are several ways in which this might be achieved. In practice what we need to know is whether any of the possible treatments saves life or reduces morbidity. Just because one centre has performed coronary artery bypass operations on a small number of highly selected patients with acute infarction ${ }^{2}$ and has achieved the remarkably low hospital mortality of $3.8 \%$ does not mean that everyone else should attempt to do the same. Those who claim that such results are possible should conduct a randomised trial to compare early operation with conservative management, and until this has been done healthy scepticism is the appropriate attitude. The intracoronary administration of streptokinase undoubtedly lyses coronary artery thrombi, ${ }^{3}$ but the evidence is conflicting on whether this improves myocardial function, ${ }^{45}$ and there is no evidence at all that it prolongs life. Until good clinical trials have been published intracoronary streptokinase should remain only a research technique, for it is expensive and in inexperienced hands it may be dangerous.

More important, with our present limited resources treating even a few patients in this way must prevent the routine investigation of other patients, from whom real benefit may be withheld - for example, those with valve disease who may need surgery or those with symptomatic coronary artery disease. One man's provision is another man's deprivation, and if extra facilities for cardiac investigation are to be provided so that many patients with suspected infarction can be studied acutely this will have to be at the expense of some other medical specialty such as geriatrics or orthopaedics. It may be that increasing cardiological rather than geriatric facilities is the right thing to do-but it cannot be justified without the appropriate clinical trials being carried out first.
According to the recent leading article in the $B M \mathcal{F},{ }^{1}$ we should "contemplate acute coronary angiography in some patients with suspected infarction," but this is precisely the sort of clinical freedom that is no longer possible or permissible. What is needed is a large multicentre trial in which a randomly selected group of patients with suspected infarction is submitted to coronary angiography and the outcome compared with that of a control group managed in the traditional, conservative manner. Until this has been done-and until it has been shown convincingly that early angiography does substantially more good than harm-no resources should be allocated nationally or appropriated locally by creating developments for such treatment.

The medical profession has always preferred to travel hopefully rather than to arrive, because arrival is often so disappointing. This habit leads to oscillating fashions, and fashion in treatment is something that we neither can nor should afford. The use of anticoagulants for the secondary prevention of myocardial infarction was largely abandoned in Britain, not because the evidence in their favour was poor (which indeed it was) but because the reduction in mortality of about $20 \%$ that anticoagulants seemed to confer was thought not to be worth the trouble. The anticoagulant fashion was followed by the antiarrhythmic fashion, but the routine use of prophylactic antiarrhythmic drugs after myocardial infarction has now mainly been given up in Britain after trials showing that these drugs do as much harm as good. ${ }^{6} 7$

Would it not have been preferable for the trials to have preceded the fashion and not vice versa? The problem, of course, is that doctors expect too much of their remedies. Although the value of prophylactic treatment of infarct survivors with a beta blocker has been better investigated than almost any treatment for any cardiovascular problem, this treatment has not yet become part of routine clinical practice -because many doctors prefer to move on to the new and unproved, which they hope will have dramatic effects, rather than to assimilate the relatively small benefits that are available from tested treatments.

The end of clinical freedom means that clinical trials and research in general have become more rather than less important, and when resources are scarce a greater proportion of them must be channelled into evaluation. If investigation and treatment are to be limited we must know which investigations and which treatments are valuable and which are not. New high cost investigational facilities (such as computed tomo- 
graphy a few years ago, or nuclear magnetic resonance scanning today) should be installed only in institutions able to evaluate them properly and with catchment areas adequate to provide the sort of patients to whom the new techniques will be applied when they become available to the average district general hospital. No new treatment (for example, coronary artery bypass grafting in patients without symptoms) should be allowed except as part of a properly conducted clinical trial, and such a trial would have to be conducted on a multicentre basis so that a wide variety of patients and medical skill would be included. Before they can be approved for prescription on a large scale new drugs need to be tested not only for efficacy but also in comparison with old drugs; a new and expensive drug can be accepted only if it is superior to an older and cheaper one. Training in evaluation techniques must form part of the education of any potential consultant; only by so doing will consultants carry through their career the habit of inquiry and scepticism that will be essential in the more restricted financial atmosphere that lies ahead.

Clinical freedom died accidentally, crushed between the rising cost of new forms of investigation and treatment and the financial limits inevitable in an economy that cannot expand indefinitely. Clinical freedom should, however, have been strangled long ago, for at best it was a cloak for ignorance and at worst an excuse for quackery. Clinical freedom was a myth that prevented true advance. We must welcome its demise, and seize the opportunities now laid out before us.

\section{J R HAMPTON}

Professor of Cardiology,

University Hospital,

Nottingham NG7 2UH

${ }^{1}$ Petch MC. Active management of myocardial infarction. $\mathrm{Br}$ Med $\mathcal{f} 1983$ 286:1841-2

${ }^{2}$ Phillips SJ, Zeff RH, Kongtahworn C, et al. Surgery for evolving myocardial infarction. $7 A M A$ 1982;248:1325-8.

${ }^{3}$ Hugenholtz PG, Rentrop P. Thrombolytic therapy for acute myocardial infarction: quo vadis? A review of the recent literature. Eur Heart $\mathcal{f}$ 1982;3:395-403.

${ }^{4}$ Khaja F, Walton JA, Brymer JF, et al. Intracoronary fibrinolytic therapy in acute myocardial infarction. Report of a prospective randomized trial. $N$ Engl f Med 1983;308:1305-11.

${ }^{5}$ Anderson JL, Marshall HW, Bray BE, et al. A randomized trial of intracoronary streptokinase in the treatment of acute myocardial infarction. $N$ Engl f Med 1983;308:1312-8.

${ }^{6}$ Chamberlain DA, Jewitt DE, Julian DG, et al. Oral mexiletine in high-risk patients after myocardial infarction. Lancet 1980;ii:1324-7.

7 Wilcox RG, Rowley JM, Hampton JR, Mitchell JRA, Roland JM, Banks DC. Randomised placebo-controlled trial comparing oxprenolol with disopyramide phosphate in immediate treatment of suspected myocardial infarction. Lancet 1980;ii:765-9.

\section{Nuclear medicine in district general hospitals}

Artificially produced radioactive isotopes were one of the benefits that came from research on atomic energy in the second world war. In medicine they were initially used in biochemical and biological research, but by the early 1950 s various diagnostic investigations had been introduced, notably in the assessment of thyroid function and in haematology. At the same time radioactive iodine was introduced for the treatment of thyrotoxicosis and some thyroid cancers, and radio- active phosphorus became available for the treatment of polycythaemia rubra vera and leukaemia. ${ }^{1}$

At that time simple external scanning procedures were available to delineate the anatomical form of the thyroid gland. Next came more complex equipment, the rectilinear scanner and later the gammacamera, which gave much more rapid and precise information. The advent of the artificial radioactive isotope technetium-99m made scanning simpler, accurate, and safe. Brain, liver, bone, and lung scanning were soon developed, and nuclear medicine can be said to have been launched as a specialty by the end of the decade. The greatest impetus for these and subsequent clinical developments occurred in the United States, with contributions from Europe, Australia, and Japan, where active departments of nuclear medicine emerged. In Britain, however, the pattern and extent of development were slow and very haphazard, though notable advances were made by a few individuals.

With nuclear medicine established as a specialty plans were clearly needed for the organisation of nuclear medicine services throughout the country-and various plans are still being produced and debated more than 20 years later. In 1970 a report by the Department of Health and Social Services (the Windeyer report $)^{2}$ recommended that each region should have a major nuclear medicine centre, from which services could be provided or supervised throughout hospitals in the rest of the region. This was never implemented, and in any event the specialty advanced so rapidly that it would not have been practicable, though some of the underlying thoughts are still pertinent. The Royal Colleges of Physicians of Edinburgh and London, and the Royal College of Physicians and Surgeons of Glasgow have considered the subject on three occasions since 1971 , looking at the training needs and defining the scope of nuclear medicine as a specialty. Their second report in 1975 strongly recommended that nuclear medicine departments should be under the charge of properly trained clinicians ${ }^{3}$ and calculated that about 80 would be needed over the next few years-at a time when over 1200 physicians in the United States were wholly practising nuclear medicine. The consultants in charge, said the colleges, would need to work harmoniously with non-medical scientists, notably physicists, chemists, and pharmacists, because nuclear medicine is more than most a multidisciplinary specialty. These proposals were widely accepted but were put into effect only in some parts of the country; in many localities arrangements are still far from satisfactory. Advice on future training programmes was given, and a specialist advisory committee in nuclear medicine was set up. The proposals recognised and welcomed the fact that clinicians from several disciplines might be interested in training for nuclear medicine, but most were expected to come from general medicine or radiology. Already, however, the numbers in training were out of step with the planned vacancies; in the mid-1970s there were too few senior registrars to fill the modest needs of the time, yet those who were trained a few years later were unable to get consultant posts because area health authorities could not afford to create them-a state of affairs that continues.

Croft ${ }^{4}$ summarised the scene in Britain in 1979 with particular respect to nuclear medicine facilities in district general hospitals, which were and still are inadequate. For an adequate service at this level he envisaged the training of either physicians who would be able to provide a comprehensive service, or radiologists who would provide just an imaging service, both on a roughly half time basis. His views and arguments have stimulated and been elaborated in a third report from the previous three royal colleges, this time in col- 